\title{
Images in Anesthesia
}

\section{Thoracic endovascular stent graft with a bird's beak sign}

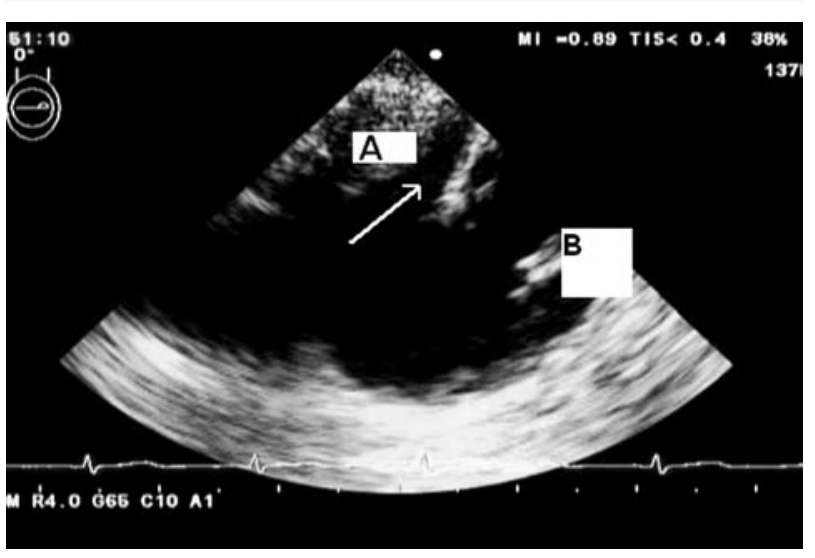

FIGURE 1 Upper esophageal transesophageal echocardiography image of the aortic arch, showing the angle between the aortic wall (A) and the stent graft (B) forming the bird'd beak sign (arrow).

CAN J ANESTH 2008/55: $11 /$ pp 785-786

A 21 yr-old male patient, with closed chest injury, presented for endovascular repair of a traumatic descending thoracic aortic pseudo-aneurysm. The preoperative computed tomography scan demonstrated the presence of a pseudo-aneurysm just distal to the left subclavian artery. It was also noted that the junction between the aortic arch and descending aorta was abnormally at a sharp right angle. Following induction of anesthesia, a transesophageal echocardiography (TEE) probe was inserted. The aortic pseudo-aneurysm was identified and the TEE deployment zone measurements were obtained. A Zenith (Cook, Inc., Bloomington, IN, USA) thoracic endovascular graft was deployed at the aortic arch proximal to the left subclavian artery, but distal to the left common carotid artery. Upper esophageal TEE views of the aortic arch demonstrated a type $\mathrm{I}^{1}$ endoleak with a right angle present between the graft and the aortic wall, leading to a bird's beak sign formation ${ }^{2}$ (Figures 1,2 and 3 ). Further ballooning of the proximal end of the graft minimized the endoleak, based on the

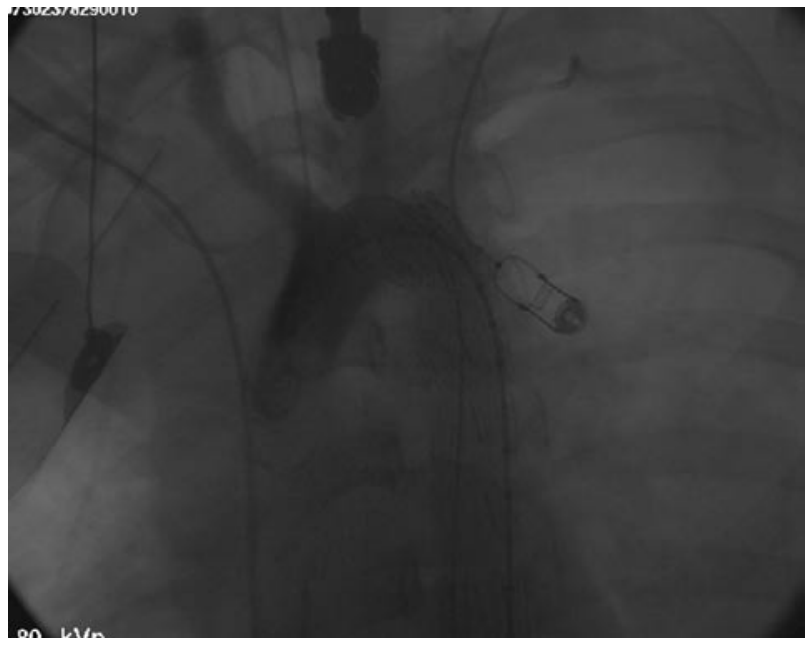

FIGURE 2 Intraoperative angiogram after the stent deployment showing the right sharp angle of the aortic arch.

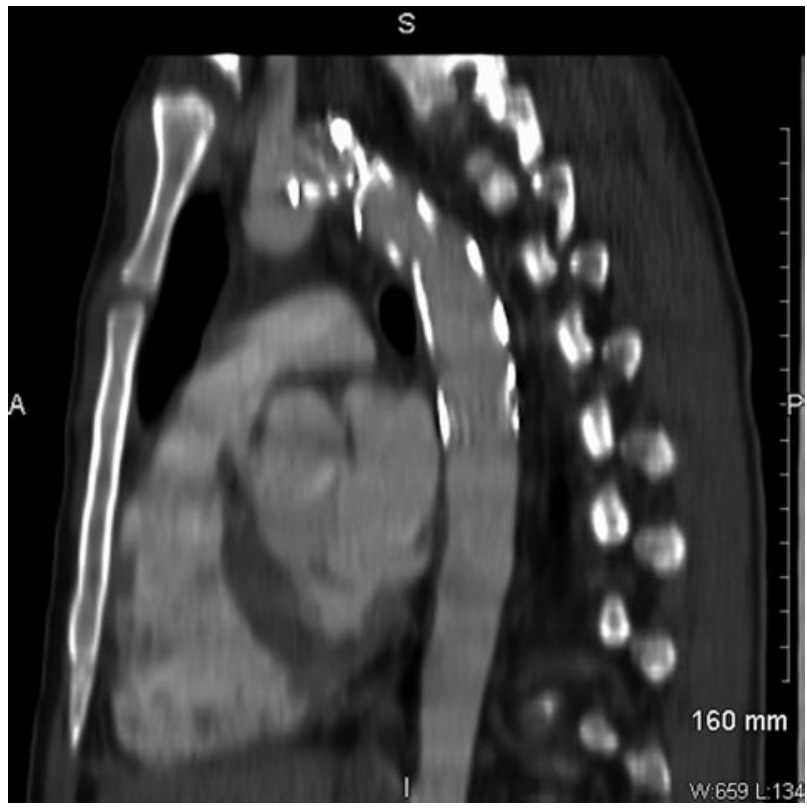

FIGURE 3 Computed tomography of the descending aorta highlighting the beaking of the proximal end of the graft in the aortic arch. 
intraoperative angiography images. There was no further change in the extent of endoleak, according to the TEE images post-ballooning. The patient's vital signs remained stable throughout the procedure, and there was no clinically significant radial-femoral arterial blood pressure gradient. At the three-month follow-up, the patient was found to have a collapsed graft with an aortic coarctation, which will require open surgical repair. The role of TEE as a diagnostic tool in detecting the long-term outcome in the presence of endoleaks warrants further evaluation.

Ashraf Fayad MD FRCPC

University of Ottawa, The Ottawa Hospital, Ottawa, Canada

E-mail: afayad@ottawahospital.on.ca

Accepted for publication August 18, 2008.

\section{References}

1 Corriere MA, Feurer ID, Becker SY, et al. Endoleak following endovascular abdominal aortic aneurysm repair: implications for duration of screening. Ann Surg 2004; 239: 805-7.

2 LePage M, Quint L, Sonnad SS, Deeb GM, Williams $D M$. Aortic dissection: CT features that distinguish true lumen from false lumen. AJR Am J Roentgenol 2001; 177: 207-11. 